\title{
Original Article \\ Law on Human Security of Prisoners in Vietnam in Current Context - Issues Raised and Direction of Completion
}

\author{
Nguyen Duc Hoa* \\ Hanoi Law University, 187 Nguyen Chi Thanh Street, Dong Da District, Hanoi, Vietnam
}

Received 14 April 2020

Revised 19 May 2020; Accepted 25 June 2020

\begin{abstract}
The article focuses on research a number of issues raised in Vietnam's legal field on human security of prisoners and based on that making offer and recommendations to contribute to the completion of this law field, this focus is mainly on completing the Law on Criminal Enforcement 2019 to contribute to the implementation of international commitments, in accordance with the country's development requirements in the new period.
\end{abstract}

Keywords: law, human security, prisoner, completion.

\footnotetext{
* Corresponding author.

Email address: ndhoa@moet.edu.vn

https://doi.org/10.25073/2588-1167/vnuls.4278
} 


\title{
Pháp luật về an ninh con người của phạm nhân ở Việt Nam trong bối cảnh hiện nay - Những vấn đề đặt ra và hướng hoàn thiện
}

\author{
Nguyễn Đức Hòa* \\ Truờng Đại học Luật Hà Nội, 187 Nguyễn Chi Thanh, quận Đống Đa, Hà Nội, Việt Nam \\ Nhận ngày 14 tháng 4 năm 2020 \\ Chỉnh sửa ngày 19 tháng 5 năm 2020; Chấp nhận đăng ngày 25 tháng 6 năm 2020
}

\begin{abstract}
Tóm tắt: Bài viết tập trung nghiên cứu một số vấn đề đặt ra trong lĩnh vực pháp luật của Việt Nam về an ninh con người của phạm nhân và trên cơ sở đó đưa ra một số đề xuất, khuyến nghị góp phần hoàn thiện lĩnh vực pháp luật này, mà tập trung chủ yếu vào việc hoàn thiện Luật thi hành án hình sự năm 2019 nhằm góp phần thực thi các cam kết quốc tế, phù hợp yêu cầu phát triển của đất nước trong thời kỳ mới.
\end{abstract}

Tù khóa: pháp luật, an ninh con người, phạm nhân, hoàn thiện pháp luật.

\section{An ninh con người và pháp luật về an ninh con người của phạm nhân - một số vấn đề lý luận và yêu cầu đặt ra trong bối cảnh mới}

Trong bối cảnh xuất hiện ngày càng nhiều những mối đe dọa đối với sự an toàn của mỗi cá nhân con người trên phạm vi toàn cầu, năm 1994, trong Báo cáo phát triển con người, Chương trình phát triển của Liên hợp quốc (UNDP) đã định nghĩa an ninh con người là "sự an toàn của con người trước các mối đe dọa kinh niên như nghèo đói, bệnh tật, đàn áp và những sự cố bất ngờ, gây tổn thương trong cuộc sống hàng ngày, dù ở trong nhà, ở nơi làm việc hay trong cộng đồng" [1]. Theo UNDP, khái niệm an ninh con người bao gồm bẩy khía cạnh: i) An ninh kinh tế; ii) An ninh lương thực; iii) An ninh sức khỏe; iv) An ninh môi trường; v) An ninh cá nhân; vi) An ninh cộng dồng và vii) An ninh chính trị. Quan niệm về an ninh con người của UNDP là một tư duy mới và nếu chúng được nhận thức đúng đắn và hành động đầy đủ sẽ mang lại những hiệu quả thiết thực đối với mỗi quốc gia, dân tộc và cộng đồng xã hội.

An ninh con người có thể được tiếp cận theo từng nhóm chủ thể xã hội. Theo đó, có thể đề cập an ninh con người của học sinh, an ninh con người của người khuyết tật, an ninh con người của người lao động di trú, an ninh con người của người nước ngoài, an ninh con người của phạm nhân...

Cho đến nay, tuy vẫn còn những cách hiểu khác nhau song khái niệm phạm nhân được đề cập trong Luật Thi hành án hình sự năm 2019 mang tính khoa học cao. Theo đó, khái niệm phạm nhân được hiểu là "người đang chấp hành án phạt tù có thời hạn, tù chung thân" (khoản 2 Điều 3) [2]. Cũng xin lưu ý thêm rằng, trong các văn kiện pháp lý quốc tế thường sử dụng khái niệm "tù nhân" hoặc "người bị cầm tù" thay vì khái niệm phạm nhân [3-4].

Một người được xác định là phạm nhân kể từ khi họ được đưa đến trại giam, cơ sở giam giữ khác (sau đây gọi tắt là trại giam) để chấp hành

\footnotetext{
* Tác giả liên hệ.

Địa chỉ email: ndhoa@moet.edu.vn

https://doi.org/10.25073/2588-1167/vnuls.4278
} 
bản án hoặc quyết định áp dụng hình phạt tù của Tòa án. Những người tuy đã bị Tòa án ra quyết định hoặc bản án phạt tù nhưng bản án đó chưa có hiệu lực pháp luật, thậm chí cả trường hợp bản án phạt tù đã có hiệu lực pháp luật nhưng người bị kết án phạt tù đang chờ quyết định đưa đi chấp hành án thì không gọi là phạm nhân. Chỉ người nào phạm tội, bị áp dụng hình phạt tù khi bản án, quyết định áp dụng hình phạt tù của Tòa án đã có hiệu lực pháp luật và đang chấp hành án phạt tù thì mới gọi là phạm nhân.

Trên cơ sở định nghĩa về an ninh con người của UNDP, căn cứ đặc điểm thi hành án phạt tù và đối tượng phạm nhân, tác giả cho rằng: An ninh con người của phạm nhân là sự an toàn về tính mạng, thân thể, bảo đảm sức khỏe thể chất và tinh thần của phạm nhân trước những tác động bất lợi của môi trường trại giam, các quan hệ cộng đồng của phạm nhân thân thiện, lành mạnh, dân chủ trong trại giam được thực hiện và phát huy, đồng thời tạo những điều kiện cho phạm nhân tái hòa nhập xã hội sau khi mãn hạn tù.

Như trên đã nói, khái niệm an ninh con người của UNDP bao gồm bẩy khía cạnh: An ninh kinh tế, an ninh lương thực, an ninh sức khỏe, an ninh môi trường, an ninh cá nhân, an ninh cộng đồng và an ninh chính trị. An ninh con người của phạm nhân là một thành tố của an ninh con người nói chung. Các khía cạnh của an ninh con người của phạm nhân sẽ được đề cập trong phần 2 của bài viết.

Môi trường trại giam gồm những con người đã từng phạm tội, thậm chí tái phạm, tái phạm nguy hiểm, ở đó hiện hữu những nguy cơ ảnh hưởng tiêu cực tới an ninh con người của phạm nhân. Cho dù phạm nhân là người đã gây hậu quả xấu cho người khác và xã hội thì họ vẫn là con người. Bị tước tự do, phạm nhân không thể tự thỏa mãn các nhu cầu tối thiểu của mình, họ hoàn toàn lệ thuộc vào nhà nước. Dưới góc độ quản lý thi hành án phạt tù, phạm nhân là người chịu sự quản lý, còn chủ thể quản lý là cơ quan thi hành án phạt tù và cán bộ trại giam: "Đây là quan hệ ra lệnh - phục tùng, không đồng cấp và có tính bắt buộc" [5]. Sự an toàn của phạm nhân trong trại giam phụ thuộc rất lớn vào tính tận tâm, trách nhiệm của đội ngũ cán bộ trại giam. Hơn nữa, trong các xã hội văn minh hiện đại, việc thi hành án phạt tù đối với người phạm tội không phải chỉ là trừng trị mà chủ yếu là giáo dục, cải tạo để họ trở thành người lương thiện, có ích cho xã hội. Vì thế, việc bảo đảm an ninh con người của phạm nhân có ý nghĩa thực tiễn trong công tác đấu tranh phòng, chống tội phạm, góp phần giảm tỷ lệ tái phạm và phạm tội mới. Đồng thời, bảo đảm quyền con người và an ninh con người đã được cộng đồng quốc tế thừa nhận, coi đó là cơ sở cho tự do, công bằng và hòa bình trên toàn thế giới. Mỗi quốc gia phải có trách nhiệm bảo đảm an ninh con người nói chung, an ninh con người của phạm nhân nói riêng.

An ninh con người của phạm nhân chỉ được bảo đảm khi hình thành được một cơ chế pháp lý để nó không bị xâm hại và trong trường hợp có vi phạm sẽ bị phát hiện kịp thời, xử lý nghiêm minh cũng như lực lượng chức năng tổ chức thực hiện các nội dung nhằm bảo đảm sự an toàn cho phạm nhân. Nói như vậy có nghĩa là việc bảo đảm an ninh con người của phạm nhân không thể thiếu pháp luật về an ninh con người của phạm nhân.

Từ đó, có thể nêu định nghĩa pháp luật về an ninh con người của phạm nhân như sau: Pháp luật về an ninh con người của phạm nhân là tổng thể các quy phạm pháp luật điều chỉnh các quan hệ xã hội phát sinh trong hoạt động thi hành án phạt tù nhằm bảo đảm an toàn cho phạm nhân trong quá trình chấp hành án phạt tù tại trại giam, đồng thời tạo điều kiện cho họ tái hòa nhập xã hội sau khi mãn hạn tù.

Trong bối cảnh toàn cầu hóa và hội nhập quốc tế ngày càng sâu rộng tác động mạnh mẽ tới sự phát triển kinh tế - xã hội và hệ thống pháp luật của các quốc gia. Tiến bộ, công bằng xã hội, dân chủ - pháp quyền, nhân quyền là xu hướng chung của nhân loại. Những áp lực từ cộng đồng quốc tế đối với sự phát triển con người trong phạm vi mỗi quốc gia ngày càng gia tăng. Yêu cầu phát triển con người không ai bị bỏ lại phía sau đòi hỏi chính phủ mỗi nước phải có những chính sách tạo cơ hội phát triển cho tất cả mọi người, nhất là những đối tượng yếu thế. Bên cạnh 
đó, những thách thức và cơ hội từ cuộc Cách mạng công nghiệp 4.0 cũng đang đặt ra những yêu cầu mới đối với việc bảo đảm an ninh con người nói chung, an ninh con người của phạm nhân nói riêng. Trước những tác động của bối cảnh mới, Văn kiện Đại hội đại biểu toàn quốc lần thứ XII của Đảng đã xác định nhiệm vụ phải "Bảo đảm an toàn xã hội, an ninh con người" [6]. Những điều này dẫn đến yêu cầu cần những thay đổi, hoàn thiện pháp luật về an ninh con người của phạm nhân trong bối cảnh mới.

\section{Thực trạng pháp luật Việt Nam hiện hành đáp ứng yều cầu bảo vệ, bảo đảm an ninh con người của phạm nhân ở Việt Nam trong bối cảnh hiện nay}

Do phạm nhân là đối tượng đang chấp hành án phạt tù tại trại giam cho nên pháp luật về an ninh con người của phạm nhân được quy định chủ yếu ở Luật Thi hành án hình sự và các văn bản hướng dẫn thi hành Luật.

\subsection{Về an ninh kinh tế, lương thưc, sức khỏe và môi trưòng}

\section{i) Các quy định về an ninh kinh tế}

Các quy định về an ninh kinh tế tạo cơ sở cho việc tổ chức các hoạt động kinh tế hoặc có liên quan đến yếu tố kinh tế của phạm nhân trong quá trình chấp hành án phạt tù và hướng tới việc tạo việc làm hoặc tìm việc làm cho người đã chấp hành xong án phạt tù.

Nghiên cứu các quy định về an ninh kinh tế của phạm nhân ở Việt Nam hiện nay cho thấy, về cơ bản các quy định này đã đáp ứng được các yêu cầu về kinh tế đối với phạm nhân, nhất là đã có tương đối đầy đủ các quy định về dạy nghề cho phạm nhân; về việc phạm nhân phải tham gia lao động bắt buộc trong điều kiện sức khỏe cho phép; về sử dụng kết quả lao động của phạm nhân; về phạm nhân được tự mình hoặc thông qua người đại diện để thực hiện giao dịch dân sự và được tham gia bảo hiểm xã hội tự nguyện, hưởng chế độ, chính sách về bảo hiểm xã hội theo quy định của pháp luật... (Điều 27, 31-34)
[2]. Đáng chú ý, trong một thời gian khá dài không có quy định về việc trả công cho phạm nhân tham gia lao động sản xuất thì đến nay đã có quy định này (khoản 1 Điều 34) [2], điều này làm cho các quy định về an ninh kinh tế của phạm nhân ở Việt Nam ngày càng tương thích hơn với pháp luật quốc tế.

Tuy nhiên, các quy định về an ninh kinh tế của phạm nhân vẫn còn bất cập ở chỗ, theo quy định hiện hành thì phạm nhân chỉ được sử dụng số tiền thưởng và số tiền được trả công khi tham gia lao động sản xuất tại trại giam vào việc mua lương thực, thực phẩm và các hàng hóa khác để phục vụ đời sống, sinh hoạt tại nơi chấp hành án hoặc gửi trại giam quản lý và được nhận lại khi chấp hành xong án phạt tù mà không được gửi số tiền này cho thân nhân của mình (khoản 2 Điều 34) [2]. Theo pháp luật quốc tế thì phạm nhân phải được phép sử dụng ít nhất một phần thu nhập của họ để mua những đồ đạc được chấp thuận để họ sử dụng riêng và để gửi một phần thu nhập của họ cho gia đình (tiết $\mathrm{b}$ Quy tắc 76) [3].

Trong thực tế giá cả hàng hóa thường có xu hướng tăng lên, do đó tiền giấy nếu đem cất đi, không lưu thông thì sẽ dần bị mất giá. Trong trường hợp phạm nhân có thu nhập hợp pháp trong trại giam mà không được gửi số tiền đó về cho gia đình hoặc không được gửi tiền tại ngân hàng hoặc không được mua vàng, bạc hay kim loại quý khác, chẳng hạn, mà buộc phải gửi tiền lưu ký tại trại giam thì vô hình trung quy định trên sẽ gây thiệt hại về kinh tế đối với những phạm nhân có thu nhập hợp pháp tại trại giam, điều này sẽ làm giảm tính tích cực của phạm nhân trong lao động sản xuất.

Bên cạnh đó, quy định về bồi dưỡng bằng tiền, hiện vật đối với phạm nhân khi lao động thêm giờ hoặc lao động trong ngày nghỉ là chưa phù hợp với thực tiễn và chưa đồng bộ với pháp luật chuyên ngành, thể hiện ở chỗ theo quy định hiện hành thì khi trực tiếp tham gia lao động sản xuất trong thời gian chính thức theo quy định, phạm nhân sẽ được trả một phần công lao động (điểm đ khoản 1 Điều 34) [2], nhưng trong trường hợp lao động thêm giờ hoặc lao động 
trong ngày nghỉ thì phạm nhân được nghỉ bù hoặc được bồi dưỡng bằng tiền, hiện vật (khoản 1 Điều 32) [2]. Rõ ràng việc được trả công lao động là khác với việc được bồi dưỡng bằng tiền hay hiện vật. Trong khi đó, theo quy định tại Điều 98 Bộ luật lao động năm 2019 thì khi làm thêm giờ vào ngày thường người lao động được trả lương ít nhất bằng $150 \%$ và vào ngày nghỉ hằng tuần ít nhất bằng $200 \%$ tính theo đơn giá tiền lương hoặc tiền lương thực trả theo công việc đang làm. Như vậy, quy định về bồi dưỡng bằng tiền, hiện vật đối với phạm nhân khi lao động thêm giờ hoặc lao động trong ngày nghỉ trong Luật Thi hành án hình sự năm 2019 là chưa đồng bộ với quy định về trả lương cho người lao động khi làm thêm giờ trong Bộ luật lao động năm 2019.

\section{ii) Các quy định về an ninh lương thục}

Các quy định về an ninh lương thực của phạm nhân ở Việt Nam là ngày càng đầy đủ hơn, mang tính nhân văn, tiến bộ thể hiện ở chỗ, so với Luật Thi hành án hình sự năm 2010, Luật Thi hành án hình sự năm 2019 đã bổ sung quy định về việc phạm nhân được bảo đảm chế độ ăn (điểm $\mathrm{b}$ khoản 1 Điều 27), coi đây là một phần quyền của phạm nhân và buộc nhà nước phải có trách nhiệm trong việc bảo đảm chế độ ăn cho phạm nhân. Đồng thời, Luật Thi hành án hình sự năm 2019 cũng quy định, ngoài tiêu chuẩn ăn theo quy định, phạm nhân được sử dụng quà, tiền của mình để ăn thêm nhưng không được quá ba lần định lượng trong 01 tháng cho mỗi phạm nhân, Giám thị trại giam có thể quyết định hoán đổi định lượng ăn cho phù hợp với thực tế để phạm nhân có thể ăn hết tiêu chuẩn (Điều 48).

Tuy vậy, Luật Thi hành án hình sự năm 2019 chỉ quy định phạm nhân được bảo đảm tiêu chuẩn định lượng về lương thực, thực phẩm, không có quy định về bảo đảm an toàn thực phẩm. Trong bối cảnh vấn đề an toàn thực phẩm ở tình trạng đáng báo động như hiện nay thì rất cần phải có quy định về vấn đề này. Luật An toàn thực phẩm năm 2010 đã dành một chương để quy định về điều kiện bảo đảm an toàn đối với thực phẩm (Chương III). Luật Thi hành tạm giữ, tạm giam năm 2015 cũng quy định: "Người bị tạm giữ, người bị tạm giam được bảo đảm an toàn thực phẩm trong ăn, uống" (khoản 3 Điều 27). Như vậy, quy định về an toàn thực phẩm cho phạm nhân tuy là rất cần thiết nhưng còn là khoảng trống trong Luật Thi hành án hình sự năm 2019.

Cũng theo quy định hiện hành, việc nấu ăn cho phạm nhân do phạm nhân đảm nhiệm dưới sự giám sát, kiểm tra của trại giam. Tuy vậy, Luật Thi hành án hình sự năm 2019 không quy định về việc trại giam cấp lương thực, thực phẩm hàng ngày cho phạm nhân phải có sự tham gia giám sát của đại diện phạm nhân, nhằm đảm bảo lương thực, thực phẩm được cấp đúng theo quy định. Ngoài ra, Luật Thi hành án hình sự năm 2019 quy định bếp ăn cho phạm nhân được cấp các dụng cụ cần thiết cho việc nấu ăn, đun nước uống và chia đồ ăn cho phạm nhân (khoản 3 Điều 48), nhưng không có quy định về việc cấp các dụng cụ phục vụ cho việc bảo quản thực phẩm cho phạm nhân. Về vấn đề này, Luật Thi hành tạm giữ, tạm giam năm 2015 quy định: "Cơ sở giam giữ tổ chức bếp ăn và được cấp các dụng cụ cần thiết cho việc bảo quản lương thực, thực phẩm, nấu ăn, nước uống và chia đồ ăn theo khẩu phần tiêu chuẩn" (khoản 3 Điều 27). Quy định nói trên trong Luật Thi hành tạm giữ, tạm giam năm 2015 là một điều cần thiết nhằm bảo đảm đồ ăn được tươi ngon, không bi ôii, thiu, mất vệ sinh đối với người sử dụng.

\section{iii) Các quy định về an ninh sức khỏe}

Khi bị vào tù nhiều phạm nhân thường mang theo những vấn đề nghiêm trọng về sức khỏe như nghiện ma túy, các bệnh tật chưa được chữa trị, các thói quen xấu có hại cho sức khỏe được hình thành trong cuộc sống trước khi vào tù $[7,97]$. Hơn nữa, trong trại giam phạm nhân phải đối mặt với rất nhiều vấn đề có thể ảnh hưởng nghiêm trọng đến sức khỏe, chẳng hạn như việc bị lây nhiễm bệnh từ những phạm nhân ở cùng phòng.

So với các quy định của pháp luật quốc tế, các quy định về an ninh sức khỏe của phạm nhân ở Việt Nam hiện nay là tương đối đầy đủ, chúng dễ dàng được tìm thấy trong Luật Thi hành án hình sự năm 2019, như: Phạm nhân được khám 
sức khỏe khi vào trại (điểm d khoản 2 Điều 28); phạm nhân là người mắc bệnh truyền nhiễm đặc biệt nguy hiểm được bố trí giam giữ riêng (điểm d khoản 2 Điều 30); phạm nhân là người đồng tính, người chuyển đổi giới tính, người chưa xác định rõ giới tính có thể được giam giữ riêng (khoản 3 Điều 30); phạm nhân được bảo đảm chế độ đồ dùng sinh hoạt cá nhân theo quy định (điểm b khoản 1 Điều 27); được hoạt động thể dục, thể thao phù hợp với điều kiện của nơi chấp hành án (Điều 50); được cấp quần áo theo mẫu thống nhất (Điều 49); được bảo đảm chế độ chăm sóc $\mathrm{y}$ tế theo quy định (điểm $\mathrm{b}$ khoản 1 Điều 27); được bảo đảm an toàn, vệ sinh lao động (khoản 1 Điều 32)... Các quy định này ngày càng đồng bộ hơn với pháp luật chuyên ngành và góp phần quan trọng trong bảo đảm sức khỏe cho phạm nhân.

Tuy nhiên, cũng còn một số nội dung về an ninh sức khỏe của phạm nhân là chưa tương thích với pháp luật quốc tế, chẳng hạn như Luật Thi hành án hình sự năm 2019 quy định chỗ nằm tối thiểu của mỗi phạm nhân là $2 \mathrm{~m}^{2}$ nhưng không quy định về số lượng tối đa phạm nhân trong một buồng giam. Nếu trong một buồng giam có quá đông phạm nhân thì sẽ ảnh hưởng hơn đến sức khỏe cũng như an ninh cá nhân của phạm nhân. Theo khảo sát của tác giả bài viết này tại một số trại giam thuộc Bộ Công an (như: Trại giam Thanh Xuân, Trại giam Hoàng Tiến, Trại giam Đồng Sơn) cho thấy đại đa số phạm nhân được khảo sát đồng ý với việc cần có quy định về giới hạn phạm nhân tối đa trong một buồng giam. Theo đó, với diện tích thông thường của các buồng giam như hiện nay thì chỉ nên có tối đa 50 phạm nhân.

Nhìn chung, những quy định về chế độ mặc và tư trang của phạm nhân trong Luật Thi hành án hình sự năm 2019 tương đối đầy đủ. Tuy vậy, vẫn còn thiếu một số đồ dùng thiết yếu cho phạm nhân như xà phòng rửa tay, dao cạo râu cho phạm nhân nam... Việc cấp những vật dụng cần thiết phục vụ cho nhu cầu vệ sinh cá nhân của phạm nhân đã được đề cập trong pháp luật quốc tế (Quy tắc 16) [3].
Mặc dù pháp luật hiện hành đã có quy định về việc phạm nhân được tham gia hoạt động thể dục, thể thao (điểm c khoản 1 Điều 27) [2] nhưng lại chưa có quy định về thời gian tập thể dục hàng ngày của phạm nhân trong điều kiện thời tiết cho phép. Về vấn đề này, pháp luật quốc tế quy định: "Mọi tù nhân không được lao động bên ngoài phải có ít nhất một giờ tập thể dục thích hợp ở ngoài trời hàng ngày nếu thời tiết cho phép... Phải có đủ không gian và trang thiết bị phục vụ mục đích này" (Quy tắc 21) [3].

Được sử dụng nước hợp vệ sinh trong tắm rửa và sinh hoạt hàng ngày là điều rất cần thiết để đảm bảo sức khỏe cho phạm nhân, nhất là phòng ngừa các bệnh ngoài da. Thực tế hiện nay ở một số trại giam đang rất thiếu nước sạch phục vụ cho nhu cầu tắm rửa và sinh hoạt của phạm nhân, buộc phạm nhân phải sử dụng cả nước không đảm bảo vệ sinh trong tắm rửa, sinh hoạt. Luật Thi hành án hình sự năm 2019 chưa có quy định về vấn đề này.

Trong xử lý phạm nhân vi phạm nội quy trại giam, Luật Thi hành án hình sự năm 2019 quy định không áp dụng cùm chân đối với phạm nhân nữ, phạm nhân là người dưới 18 tuổi, phạm nhân là người già yếu trong thời gian bị giam tại buồng kỷ luật (khoản 2 Điều 43). Tuy nhiên, Luật chưa có quy định về việc có cùm chân đối với người chuyển đổi giới tính (chẳng hạn chuyển đổi từ nữ sang nam) vi phạm nội quy trại giam bị giam tại buồng kỷ luật hay không. Ngoài ra, Luật Thi hành tạm giữ, tạm giam năm 2015 quy định không áp dụng cùm chân đối với người bị kỷ luật là người khuyết tật nặng trở lên (khoản 3 Điều 23), Luật Thi hành án hình sự năm 2019 cũng chưa có quy định này.

\section{iv) Các quy định về an ninh môi trường}

Hiến pháp năm 2013 đã chế định quyền và nghĩa vụ của mọi người đối với môi trường tại Điều 43: Mọi người có quyền được sống trong môi trường trong lành và có nghĩa vụ bảo vệ môi trường. Việc bảo vệ, giữ gìn môi trường trại giam và môi trường buồng giam là rất cần thiết để bảo đảm sức khỏe cho phạm nhân. Buồng giam do có nhiều người cùng ở và sinh hoạt chung trong 
một không gian chật hẹp rất cần những quy định cụ thể về việc giữ gìn môi trường như không được hút thuốc, có ý thức giữ gìn vệ sinh chung; việc phun thuốc phòng dịch cũng cần được tiến hành theo định kỳ. Môi trường trại giam đảm bảo sạch sẽ, vệ sinh môi trường và cảnh quan tự nhiên.

Luật Thi hành án hình sự năm 2019 chưa quy định đầy đủ các nội dung có liên quan tới an ninh môi trường của phạm nhân trong trại giam. Trong các quyền của phạm nhân được quy định tại Điều 27 Luật Thi hành án hình sự năm 2019 chưa có quy định về việc phạm nhân có quyền được sống trong môi trường trong lành và các nội dung về bảo vệ môi trường trại giam.

\subsection{Các quy định về an ninh cá nhân, cộng đồng và chính trị}

\section{i) Các quy định về an ninh cá nhân}

An ninh cá nhân của phạm nhân là sự an toàn về tính mạng, thân thể, sức khỏe của phạm nhân trong mọi hoàn cảnh khỏi sự tùy tiện, lạm quyền của trại giam và cán bộ trại giam cũng như sự xâm hại hay đe dọa xâm hại bởi các phạm nhân khác trong trại giam.

Các quy định của pháp luật hiện hành về an ninh cá nhân của phạm nhân ngày càng đồng bộ với pháp luật chuyên ngành và tương thích với pháp luật quốc tế, thể hiện: Luật Thi hành án hình sự năm 2019 ngoài việc bổ sung quy định về nghiêm cấm hành vi tra tấn và các hình thức đối xử hoặc trừng phạt tàn bạo, vô nhân đạo hoặc hạ nhục người chấp hành án (khoản 8 Điều 10) còn có các quy định khác nhằm bảo đảm an ninh cá nhân của phạm nhân như: cấm phạm nhân mang các vật cấm vào trại giam (điểm c khoản 3 Điều 28); về quản lý đặc biệt những phạm nhân không chịu cải tạo, vi phạm nội quy trại giam (khoản 1 Điều 43)...

Tuy vậy, có một số nội dung là chưa thật đầy đủ và cụ thể, chẳng hạn như chưa có quy định về việc kiểm soát an ninh đối với thân nhân phạm nhân khi thăm gặp phạm nhân. Trong thực tế, có những trường hợp thân nhân phạm nhân không tuân thủ đầy đủ các quy định về thăm gặp phạm nhân, đưa vật cấm cho phạm nhân trong thăm gặp, vì vậy cần phải có quy định cụ thể để phòng ngừa hiện tượng này. Đồng thời, theo quy định của Luật Thi hành án hình sự năm 2019 (điểm c khoản 2 Điều 28) thì khi tiếp nhận người chấp hành án phạt tù, trại giam có trách nhiệm kiểm tra người chấp hành án phạt tù; kiểm tra và xử lý đồ vật mang theo trước khi đưa vào buồng giam. Tuy nhiên, Luật lại không có quy định về giới tính của người kiểm tra đối với người chấp hành án phạt tù. Luật Thi hành tạm giữ, tạm giam năm 2015 quy định rõ, khi tiếp nhận người bị tạm giữ, người bị tạm giam, cơ sơ giam giữ có trách nhiệm kiểm tra thân thể của người bị tạm giữ, người bị tạm giam. Việc kiểm tra thân thể người bị tạm giữ, người bị tạm giam là nam giới do cán bộ nam thực hiện, nữ giới do cán bộ nữ thực hiện và được tiến hành ở nơi kín đáo (khoản 2 Điều 16). Như vậy, quy định về kiểm tra thân thể đối với phạm nhân là chưa chặt chẽ để phòng ngừa hiện tượng xâm phạm thân thể, nhân phẩm phạm nhân.

Cũng nhằm phòng ngừa hiện tượng xâm phạm thân thể, lạm dụng tình dục đối với phạm nhân nữ, pháp luật quốc tế quy định phạm nhân nữ chỉ do cán bộ nữ quản lý (tiết c, Quy tắc 53) [3]. Luật Thi hành án hình sự năm 2019 chưa quy định về vấn đề này.

Theo quy định của pháp luật hiện hành, trong trường hợp phạm nhân nữ có thai hoặc đang nuôi con nhỏ dưới 36 tháng tuổi mà vi phạm nội quy trại giam thì sẽ bị giam tại buồng kỷ luật (khoản 2 Điều 43) [2]. Pháp luật quốc tế quy định, không bao giờ áp dụng hình phạt biệt giam (giam trong buồng kín) hoặc kỷ luật bằng cách cách ly đối với tù nhân nữ mang thai, có con nhỏ và đang cho con bú (Quy tắc 22) [8]. Như vậy, quy định về xử lý phạm nhân nữ có thai hoặc đang nuôi con nhỏ vi phạm kỷ luật là chưa tương thích với pháp luật quốc tế.

Ngoài ra, như trên đã nói, Luật Thi hành án hình sự năm 2019 đã bổ sung quy định về nghiêm cấm hành vi tra tấn và các hình thức đối xử hoặc trừng phạt tàn bạo, vô nhân đạo hoặc hạ nhục người chấp hành án, đây là một điều cần thiết song lại chưa có quy định về việc nghiêm 
cấm thực hiện các thí nghiệm y học có thể gây nguy hại cho sức khỏe của phạm nhân. Pháp luật quốc tế đã quy định rõ, không người bị giam hay bị cầm tù nào phải chịu bất kỳ một cuộc thí nghiệm y tế hay khoa học nào có thể gây nguy hại cho sức khỏe của mình, dù cho người đó đồng ý (Nguyên tắc 22) [9]. Đây là điều khuyết thiếu cần phải bổ sung.

\section{ii) Các quy định về an ninh cộng đồng}

An ninh cá nhân có liên quan rất mật thiết với an ninh cộng đồng, do đó trong trại giam phải xây dựng được một môi trường nhân văn và các quan hệ xã hội lành mạnh, thân thiện, góp phần hướng thiện cho phạm nhân.

Trước hết, giáo dục có vai trò trang bị tri thức, hình thành nhân cách, bồi bổ tâm hồn, định hướng niềm tin, giá trị, hình thành lối sống, văn hóa ứng xử của mỗi người, trong đó có phạm nhân. Đồng thời, việc được tham gia các hoạt động thể dục, thể thao, sinh hoạt văn hóa, văn nghệ cũng góp phần gắn kết phạm nhân với nhau. Việc được liên lạc, tiếp xúc với gia đình làm cho phạm nhân ổn định hơn về mặt tâm lý. Trong công tác giáo dục cải tạo phạm nhân cũng như bảo đảm an ninh con người cho phạm nhân nhất thiết phải có các quy định về những vấn đề này.

Luật Thi hành án hình sự năm 2019 quy định, phạm nhân phải học pháp luật, giáo dục công dân và được học văn hóa, học nghề; phạm nhân chưa biết chữ phải học văn hóa để xóa mù chữ (khoản 1 Điều 33); phạm nhân được hoạt động thể dục, thể thao, sinh hoạt văn hoá, văn nghệ, đọc sách, báo, nghe đài, xem truyền hình phù hợp với điều kiện của nơi chấp hành án (khoản 1 Điều 50); được duy trì các mối liên lạc với gia đình (Điều 52); phạm nhân theo tôn giáo được sử dụng kinh sách xuất bản dưới hình thức sách in, phát hành hợp pháp và được bày tỏ niềm tin tín ngưỡng, tôn giáo theo quy định của pháp luật về tín ngưỡng, tôn giáo (Khoản 3 Điều 50). Các quy định nói trên có tác dụng rất quan trong trong việc gắn kết phạm nhân với nhau và với cán bộ trại giam, hình thành các mối quan hệ tốt đẹp trong trại giam, tác động tích cực tới quá trình cải tạo của phạm nhân.
Tuy vậy, theo quy định của pháp luật hiện hành thì phạm nhân chỉ được sử dụng kinh sách và bày tỏ niềm tin tín ngưỡng, tôn giáo mà không được thực hiện các nghi lễ tôn giáo (khoản 5 Điều 6) [10]. Pháp luật quốc tế rất chú trọng tới việc đáp ứng nhu cầu tín ngưỡng, tôn giáo của phạm nhân như: Cần phải tôn trọng tín ngưỡng và giáo lý của tù nhân (tiết b Quy tắc 6) [3]; Tín ngưỡng và tập quán văn hóa của nhóm mà tù nhân đó là một thành viên cần được tôn trọng, ở bất cứ nơi nào mà hoàn cảnh địa phương yều cầu như vậy (Nguyên tắc 3) [4]; Trong chừng mực có thể thực hiện được, mọi tù nhân phải được thỏa mãn những nhu cầu đời sống tín ngưỡng bằng việc tham gia các buổi lễ tổ chức trong nhà tù, được sở hữu sách kinh của tôn giáo và giáo phái của người đó (Quy tắc 42) [3]... Thậm chí, theo quy định của pháp luật quốc tế, đối với những nhà tù có đông tù nhân theo một tôn giáo hay tín ngưỡng nào đó thì cần cử ra một người đại diện và người này làm việc toàn thời gian trong việc phục vụ các nhu cầu về tín ngưỡng, tôn giáo cho cộng đồng phạm nhân này (Quy tắc 41) [3]. Như vậy, quy định về việc thực hiện các nghi lễ tôn giáo của phạm nhân trong Luật Thi hành án hình sự năm 2019 là chưa tương thích với pháp luật quốc tế. Nghị quyết Đại hội đại biểu toàn quốc lần thứ XII của Đảng đã khẳng định: "Phát huy các giá trị, nhân tố tích cực trong văn hóa tôn giáo, tín ngưỡng" [6]. Một trong những điểm tích cực nổi bật của tôn giáo là tính hướng thiện và điều này càng cần được khuyến khích trong công tác giáo dục cải tạo phạm nhân, nhằm hướng thiện cho phạm nhân và xây dựng môi trường trại giam an toàn, nhân văn, lành mạnh.

Luật Thi hành án hình sự năm 2019 quy định, phạm nhân được gặp và liên lạc điện thoại trong nước với thân nhân trong quá trình chấp hành án tại trại giam (Điều 52 và Điều 54). Tuy nhiên, văn bản luật này không nói rõ thân nhân của phạm nhân là gồm những đối tượng nào. Bộ luật Tố tụng hình sự năm 2015 và Luật Thi hành tạm giữ, tạm giam năm 2015 đều quy định cụ thể về vấn đề này.

Theo quy định tại Điều 54 Luật Thi hành án hình sự năm 2019, mỗi tháng phạm nhân được 
gửi 02 lá thư và được liên lạc điện thoại trong nước với thân nhân 01 lần, mồi lần không quá 10 phút, trừ trường hợp cấp bách. Chi phí cho việc liên lạc của phạm nhân do phạm nhân chi trả. Với quy định này, những phạm nhân không có hoặc không còn khả năng lao động mà có hoàn cảnh kinh tế gia đình khó khăn, không có điều kiện chu cấp cho phạm nhân thì họ khó có thể thực hiện được việc liên lạc điện thoại với thân nhân của mình. Về vấn đề này, pháp luật quốc tế quy định, phạm nhân "phải được tạo ra cơ hội đầy đủ để liên lạc với thế giới bên ngoài” (Nguyên tắc 19) [9]. Thiết nghĩ cũng nên hoàn thiện quy định về liên lạc của phạm nhân cho phù hợp với từng nhóm đối tượng phạm nhân.

Ngoài ra, theo quy định của pháp luật hiện hành, trong trường hợp phạm nhân nữ vi phạm nội quy trại giam, bị giam tại buồng kỷ luật thì không được gặp thân nhân (khoản 2 Điều 43) [2]. Trong khi đó, pháp luật quốc tế quy định, các hình thức xử phạt kỷ luật đối với tù nhân nữ không được bao gồm việc cấm liên lạc với gia đình, đặc biệt là với trẻ em (Quy tắc 23) [8]. Như vậy, quy định về liên lạc với thân nhân đối với phạm nhân nữ khi bị kỷ luật trong pháp luật Việt Nam hiện hành chưa tương thích với pháp luật quốc tế.

\section{iii) Các quy định về an ninh chính trị}

Chúng tôi cho rằng an ninh chính trị của phạm nhân chứa đựng yếu tố dân chủ trong trại giam, trong đó không có sự lạm quyền, hách dịch, nhũng nhiễu của trại giam và cán bộ trại giam đối với phạm nhân, phạm nhân có điều kiện bày tỏ nguyện vọng và chính kiến của mình về các vấn đề có liên quan đến quyền, lợi ích hợp pháp của mình, việc thực hiện các quy định của pháp luật về an ninh con người của phạm nhân phải được giám sát chặt chẽ bảo đảm đúng quy định của pháp luật.

Các quy định của Luật Thi hành án hình sự năm 2019 đã thể hiện rất rõ về dân chủ trong thi hành án hình sự, trong đó có thi hành án phạt tù như: quy định trách nhiệm của trại giam khi tiếp nhận người chấp hành án phạt tù là phải giải thích quyền, nghĩa vụ cho họ, trong đó có quyền khiếu nại, tố cáo (điểm đ khoản 1 Điều 28); phạm nhân được bảo đảm quyền khiếu nại, tố cáo (điểm $\mathrm{g}$ khoản 1 Điều 27); quy định về thẩm quyền giải quyết khiếu nại, tố cáo (điểm $h$ khoản 1 Điều 192); quy định về chủ thể giám sát hoạt động thi hành án phạt tù (Điều 6)... Như vậy, các quy định về an ninh chính trị của phạm nhân ngày càng đầy đủ và phù hợp hơn với thực tiễn.

Tuy nhiên, có một số nội dung là chưa khoa học và chưa tương thích với pháp luật quốc tế, cụ thể là: Theo quy định của pháp luật, phạm nhân có quyền khiếu nại, tố cáo. Viện trưởng Viện kiểm sát có thẩm quyền giải quyết tố cáo đối với hành vi vi phạm pháp luật trong quản lý, giáo dục phạm nhân của người được giao quản lý, giáo dục phạm nhân (điểm h Điều 192) [2]. Nhưng theo quy định, mọi đơn, thư của pham nhân đều phải được Giám thị trại giam kiểm tra, kiểm duyệt trước khi chúng được gửi đi (khoản 1 Điều 54) [2]. Trong trường hợp phạm nhân có đơn tố cáo chính Giám thị trại giam, chẳng hạn, thì liệu đơn tố cáo đó có được kịp thời gửi đến cơ quan, người có thẩm quyền để giải quyết? Theo quy định của pháp luật quốc tế, phạm nhân cần được gửi đơn tới các cơ quan có thẩm quyền bên ngoài nhà tù mà không bị kiểm duyệt nội dung (Quy tắc 36) [3]. Như vậy, quy định về việc kiểm duyệt đơn, thư khiếu nại, tố cáo của phạm nhân trong Luật Thi hành án hình sự năm 2019 là chưa đảm bảo tính khoa học và chưa tương thích với pháp luật quốc tế.

Luật Thi hành án hình sự năm 2019 có các quy định về khiếu nại, tố cáo và giải quyết khiếu nại, tố cáo của phạm nhân. Song hiện chưa có quy định về việc phạm nhân không biết chữ hoặc không biết tiếng Việt (phạm nhân là người dân tộc thiểu số hoặc phạm nhân là người nước ngoài) thì được thực hiện quyền khiếu nại, tố cáo bằng lời nói có phiên dịch. Theo quy định của pháp luật quốc tế, đối với phạm nhân không biết tiếng phổ thông và phạm nhân nước ngoài được tố cáo bằng lời nói, hoặc có phiên dịch (Quy tắc 35) [3], (Nguyên tắc 14) [9]. Như vậy, so với tiêu chuẩn quốc tế, Luật Thi hành án hình sự năm 2019 đang còn thiếu quy định về việc tạo điều kiện cho những phạm nhân không biết chữ hoặc 
không biết tiếng Việt được thực hiện tố cáo bằng lời nói hoặc có phiên dịch.

Ngoài ra, Luật Thi hành án hình sự hiện hành cũng chưa quy định về việc giám sát của đại biểu Quốc hội và đại biểu Hội đồng nhân dân (đại biểu dân cử) đối với thi hành án hình sự, trong đó có những nội dung liên quan đến thi hành án phạt tù và bảo đảm an ninh con người của phạm nhân. Trong khi đó, Bộ luật tố tụng hình sự năm 2015 và Luật Tổ chức cơ quan điều tra hình sự năm 2015 đều quy định về vấn đề này.

Như vậy, chúng ta thấy pháp luật về an ninh con người của phạm nhân ở Việt Nam hiện nay khá toàn diện và đầy đủ, ngày càng thống nhất, đồng bộ với pháp luật chuyên ngành. Hầu hết các nội dung quan trọng về an ninh con người của phạm nhân đã được quy định trong văn bản luật. Tuy nhiên, vẫn còn một số quy định bất cập và chưa tương thích với pháp luật quốc tế, cần phải tiếp tục được hoàn thiện, góp phần bảo đảm an ninh con người của phạm nhân được tốt hơn.

\section{Một số hướng hoàn thiện các quy định về an ninh con người của phạm nhân trong Luật Thi hành án hình sự năm 2019}

Trên cơ sở những bất cập đã phân tích ở trên, tác giả đề xuất một số hướng hoàn thiện pháp luật về an ninh con người của phạm nhân ở Việt Nam hiện nay như sau:

Một là, cần mở rộng quyền định đoạt của phạm nhân đối với số tiền hợp pháp phạm nhân nhận được tại trại giam theo hướng cho phép phạm nhân được gửi số tiền đó cho thân nhân của mình hoặc gửi tiền vào tài khoản ngân hàng nếu phạm nhân có nguyện vọng hoặc gửi lưu ký tại trại giam hoặc mua vàng, các tài sản có giá trị khác. Điều này sẽ kích thích tính tự giác của phạm nhân trong lao động sản xuất và tạo điều kiện thuận lợi hơn cho việc tái hòa nhập xã hội của người đã chấp hành xong án phạt tù. Nghiên cứu sửa đổi quy định về bồi dưỡng bằng tiền, hiện vật đối với phạm nhân khi lao động thêm giờ hoặc lao động trong ngày nghỉ trong Luật Thi hành án hình sự năm 2019 cho phù hợp với quy định về trả lương cho người lao động khi làm thêm giờ trong Bộ luật lao động năm 2019. Đồng thời, nghiên cứu bồ sung các quy định về bảo đảm an toàn thực phẩm cho phạm nhân; về việc phạm nhân tham gia giám sát về định lượng lương thực, thực phẩm cấp cho phạm nhân và về cấp dụng cụ để bảo quản thực phẩm cho phạm nhân.

Hai là, cần có quy định về số lượng tối đa phạm nhân trong một buồng giam nhằm tránh tình trạng giam giữ quá đông phạm nhân trong một buồng giam dễ làm ảnh hưởng đến sức khỏe cũng như nảy sinh các nguy cơ gây mất an ninh cá nhân của phạm nhân; bổ sung các quy định về thời gian tập thể dục, thể thao của phạm nhân; về cấp các vật dụng cần thiết và nước hợp vệ sinh phục vụ nhu cầu vệ sinh cá nhân của phạm nhân và về không áp dụng cùm chân đối với phạm nhân bị kỷ luật là người khuyết tật nặng trở lên.

Để bảo vệ, giữ gìn môi trường trại giam bảo đảm sức khỏe cho phạm nhân cần bồ sung quy định về quyền và nghĩa vụ của phạm nhân đối với bảo vệ môi trường trại giam, đồng thời cần có quy định cụ thể về việc xây dựng hệ thống xử lý nước thải bảo đảm môi trường trại giam.

Ba là, bổ sung quy định về việc kiểm soát an ninh đối với thân nhân phạm nhân khi thăm gặp phạm nhân, phòng ngừa hiện tượng thân nhân phạm nhân đưa vật cấm cho phạm nhân trong quá trình thăm gặp và quy định về việc kiểm tra thân thể người chấp hành án phạt tù là nam giới do cán bộ nam thực hiện, nữ giới do cán bộ nữ thực hiện nhằm phòng ngừa xâm hại thân thể và bảo đảm tôn trọng nhân phẩm, danh dự của phạm nhân.

Hoàn thiện quy định về phòng, chống lạm dụng tình dục đối với phạm nhân nữ theo hướng quy định về việc cán bộ nữ quản lý phạm nhân nữ, không bố trí cán bộ nam quản lý phạm nhân nữ, trong trường hợp có bố trí cán bộ nam quản lý phạm nhân nữ thì phải có cán bộ nữ cùng phối hợp quản lý phạm nhân nữ. Nghiên cứu bỏ quy định về giam phạm nhân nữ có thai hoặc đang nuôi con nhỏ dưới 36 tháng tuổi vi phạm nội quy trại giam tại buồng kỷ luật và bổ sung quy định về nghiêm cấm tiến hành thí nghiệm y tế hay khoa học nào có thể gây nguy hại cho sức 
khỏe của phạm nhân cho phù hợp với pháp luật quốc tế.

Bốn là, nghiên cứu cho phép phạm nhân được thực hiện các nghi lễ tôn giáo trong điều kiện thực tế cho phép và bổ sung quy định về thân nhân của phạm nhân là gồm những người nào để các trại giam và thân nhân của phạm nhân thực hiện thống nhất. Để tăng cường mối liên hệ giữa phạm nhân với gia đình phạm nhân giúp cho việc chấp hành án của phạm nhân được tốt hơn, thiết nghĩ cần bổ sung quy định về việc cho phép những phạm nhân không có hoặc không còn khả năng lao động mà có hoàn cảnh kinh tế gia đình khó khăn, không có điều kiện chu cấp cho phạm nhân thì được gửi thư và gọi điện thoại cho thân nhân với số lần và thời gian nhất định không phải nộp phí. Cũng cần bỏ quy định về việc cấm liên lạc với gia đình đối với phạm nhân nữ vi phạm nội quy trại giam cho phù hợp với các quy định của các văn bản pháp lý quốc tế như: Các quy tắc tiêu chuẩn tối thiểu về đối xử với tù nhân năm 1955; Tập hợp các nguyên tắc về bảo vệ tất cả những người bị giam hay bị cầm tù dưới bất kỳ hình thức nào năm 1988; Những quy tắc của Liên Hiệp quốc trong việc đối xử đối với tù nhân nữ và các biện pháp không giam giữ đối với nữ tội phạm năm 2010.

Năm là, hoàn thiện cơ chế kiểm sát của Viện kiểm sát nhân dân đối với công tác thi hành án phạt tù bảo đảm phát hiện kịp thời những hành vi xâm hại an ninh con người của phạm nhân mà cụ thể là bổ sung quy định về đặt hòm thư của Viện kiểm sát tại trại giam để tiếp nhận khiếu nại, tố cáo của phạm nhân và quy định về việc trại giam tổ chức đối thoại với phạm nhân phải mời đại diện Viện kiểm sát dự theo dõi; bổ sung quy định về việc phạm nhân là người dân tộc thiểu số hoặc phạm nhân là người nước ngoài không biết tiếng Việt được thực hiện quyền khiếu nại, tố cáo bằng lời nói hoặc có phiên dịch, đồng thời bổ sung quy định về chủ thể giám sát là đại biểu dân cử đối với thi hành án hình sự trong đó có thi hành án phạt tù nhằm tăng cường trách nhiệm của những đại biểu này đối với việc bảo đảm an ninh con người của phạm nhân./.

\section{Tài liệu tham khảo}

[1] Chương trình phát triển Liên Hợp quốc, Báo cáo phát triển con người (1994), NewYork, Oxford University Press.

[2] Luật Thi hành án hình sự năm 2019.

[3] Liên Hợp quốc, Các quy tắc tiêu chuẩn tối thiểu về đối xử với tù nhân năm 1955.

[4] Liên Hợp quốc, Những nguyên tắc cơ bản trong việc đối xử với tù nhân năm 1990.

[5] Học viện Cảnh sát Nhân dân, Giáo trình môn học Quản lý nhà nước về an ninh quốc gia, trật tự, an toàn xã hội, Hà Nội, 2010.

[6] Đảng Cộng sản Việt Nam, Văn kiện Đại hội đại biểu toàn quốc lần thứ XII, NXB Chính trị quốc gia - Sự thật, Hà Nội, 2016.

[7] Andrew Coyle, Nhân quyền trong công tác quản lý trại giam, Học viện Cảnh sát nhân dân dịch và hiệu đính, 2007.

[8] Liên Hợp quốc, Những quy tắc trong việc đối xử đối với tù nhân nữ và các biện pháp không giam giữ đối với nữ tội phạm năm 2010.

[9] Liên Hợp quốc, Tập hợp các nguyên tắc về bảo vệ tất cả những người bị giam hay bị cầm tù dưới bất kỳ hình thức nào năm 1988.

[10] Luật Tín ngưỡng, tôn giáo năm 2016. 